\title{
Battery System Design for Electric Go-Kart
}

\author{
Krzysztof MATEJA ${ }^{1}$ \\ Silesian University of Technology, Faculty of Mechanical Engineering, Poland
}

\begin{abstract}
This article presents the results of work related to power supply system for electric go-kart. The power supply system is composed of battery cells, BMS (Battery Management System) and a DC/DC converter for some peripheral devices. During the design of the system, various possibilities of energy storage were considered, based in particular on different types of batteries. The MBD (ModelBased Design) methodology was used to develop the power supply system, consisting in the development of a simulation model of the system and the study of the space of possible solutions with the use of these models. The model of the drive system determined the energy demand to obtain the required power, torque and rotational speed for a given trajectory. Various driving scenarios were analyzed. On their example, we developed models showing the energy demand for given route. The results show the estimated driving time for various conditions. The system operating time may be shorter or extended. It depend on the driving style and the nature of the route. The developed simulation model allowed to select appropriate parameters of the power supply system and the drive system so as to meet the criteria assumed.
\end{abstract}

Keywords. Electric go-kart, Light electric vehicle, EV, power supply system, battery cell, LTO, LFP

\section{Introduction}

Electric vehicles are gaining more and more popularity. Electromobility is becoming an everyday form of mobility, making life easier for the user thanks to the gradually introduced autonomy. Electric powered vehicles are not only cars, but also vehicles that are used in the entertainment industry - scooters, skateboards, buggies, go-karts [1,2]. Electric vehicle power supply system is most often based on battery cells. Various types of cells have a number of limitations related to energy and power density, mass, charging and discharging currents, number of charging cycles, and meeting safety requirements. Appropriate selection and connection of cells into modules has crucial meaning for the subsequent operation of the system. The aim is to ensure the longest possible operation of the system. Currently, the most commonly used cells in vehicles are Li-Ion cells. They are used mainly due to the high energy and power density, long life cycle and no memory effect. As a result, Li-Ion batteries can be smaller and take up less space than batteries made of other cells $[3,4]$. Li-Ion cells used in the automotive industry are not the safest. There have been many cases of Li-ion batteries catching fire and exploding in vehicles. They are associated with various incidents: short circuits, mechanical damage, manufacturing defects $[5,6]$. Mechanical damage is type of defect that is most likely to occur in kart racing. Another issue in the case of electric go-karts for entertainment

\footnotetext{
${ }^{1}$ Corresponding Author, Mail: krzysztof.mateja@polsl.pl.
} 
purposes is to ensure operation for at least one race (8-10 minutes) so that during the ride there is no need to recharge the cells or replace them.

In order to develop a model of power supply system cooperating with drive system, it was decided to use Model Based Design (MBD) method [7-12]. MBD method is often used to design complex mechatronic systems. The use of such a methodology is particularly advantageous when designing systems require cooperation with specialists from various fields. An example would be drive system, power supply system, and electronics. An innovative approach to solving the problem will allow to develop subsystem models and then integrate them into one system.

\section{Energy demand}

The power supply system for electric go-karts is dependent on several limitations, related to dimensions, weight, cell efficiency and range. The main problem that occurs in case of electric go-karts power supply system is the limited capacity of batteries, which results in a limited driving time [13]. The challenge is to ensure the longest possible operation time, quick charging and reduce weight of the vehicle. Mass of batteries should not be significant in relation to the weight of entire vehicle. These requirements are often contradictory, so in order to choose the right components and settings, we should looking for "golden mean" consisting in choosing the most optimal version.

The first way is to assemble a large number of battery cells. A large number of cells connected in parallel will increase capacity of battery, which will extend working time. The disadvantage is the mass of battery packs. Too much weight causes a greater load and faster wear of components, among others bearings, tires.

Another way is possibility of using cells with high charging currents. Certain limitations should be taken into account here, i.e. battery capacity, decrease in cell efficiency over time, reduce the number of charging cycles, differences in the internal structure of the cell due to the temperature, higher range or lack of charging infrastructure.

The last method taken into account is modular design of battery packs. It should ensure quick assembly and disassembly of batteries. Thanks to this solution, it will be possible to remove a discharged batteries and connect it to charging, and install a charged batteries. It is also possible to use a hybrid of above methods.

\section{Concept model of power supply system}

The initial works began with general operation diagram of the power supply system. Into this scheme drive system and other energy consumption sources was included. We took into account also all the elements that should be included in the system (Fig. 1).

The most important issue in the development of power supply system are battery cells, and more precisely the type that will be used. In order to select the most appropriate cells, it was decided to use morphological analysis. Analysis included among others performance, safety, cost, lifespan, power and energy density, operating temperature, charging times. The most important criterion was the safety of the vehicle users. For this reason, the cell types that meet high safety standards have been reduced to two cell types - LTO ( $\mathrm{Li}_{4} \mathrm{Ti}_{5} \mathrm{O}_{12}$ - Lithium Titanate) and LFP ( $\mathrm{LiFePo}_{4}$ - Lithium Iron Phosphate). These two types compared to the other cells considered do not burn and do not explode. Number of cycles for both types is high, the operating temperature range of cells is also 
very wide and sufficient to work in the initially assumed conditions. Comparing LTO and LFP cells, it can be seen that the biggest difference, and also the disadvantage of LTO cells, is their high price. LTO cell costs almost four time more than LFP per Ah (Wh). On the other hand efficiency, high charging and discharging currents work in favor of the $\mathrm{Li}_{4} \mathrm{Ti}_{5} \mathrm{O}_{12}$ (Fig.2). Considering number of cycles and the cost per cycle, LTO is cheaper than LFP. Longer working time of $\mathrm{Li}_{4} \mathrm{Ti}_{5} \mathrm{O}_{12}$ causes that this technology is even 3 times cheaper than $\mathrm{LiFePO}_{4}$. This comparison takes into account all lifespan of batteries.

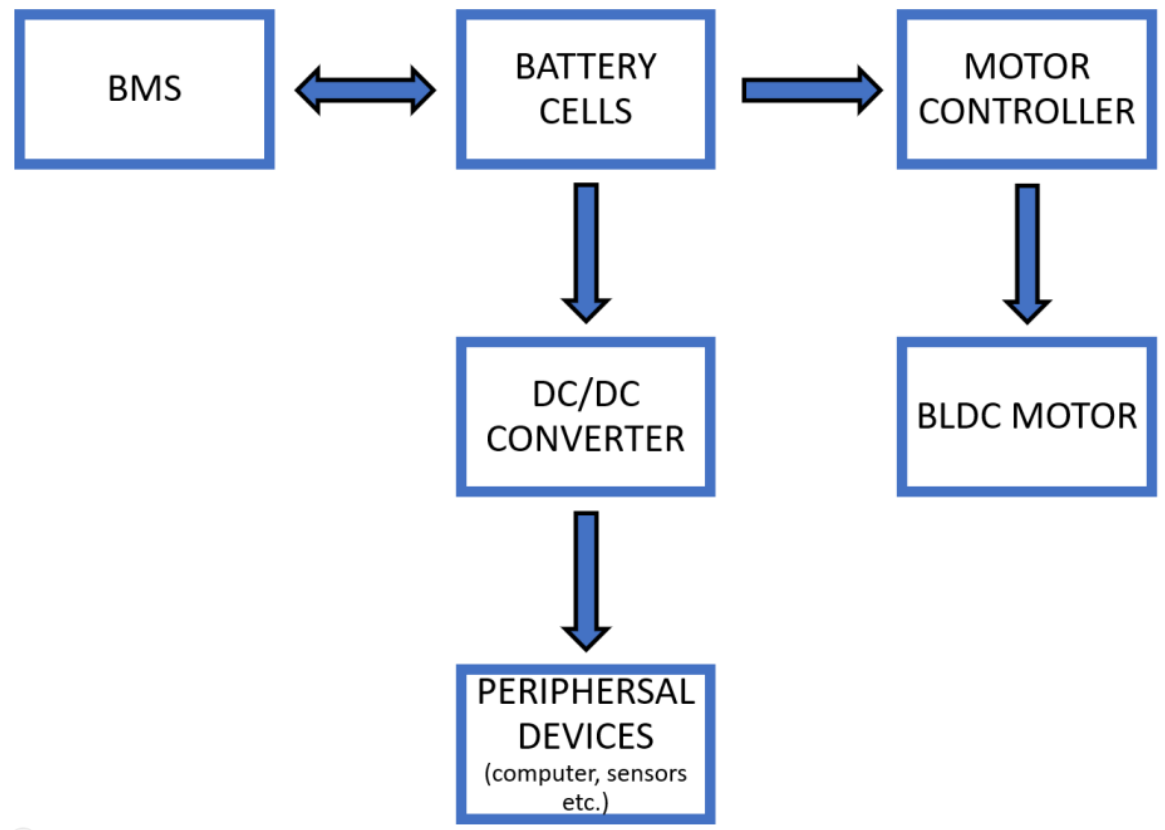

Figure 1. General diagram of the electric go-kart power supply system
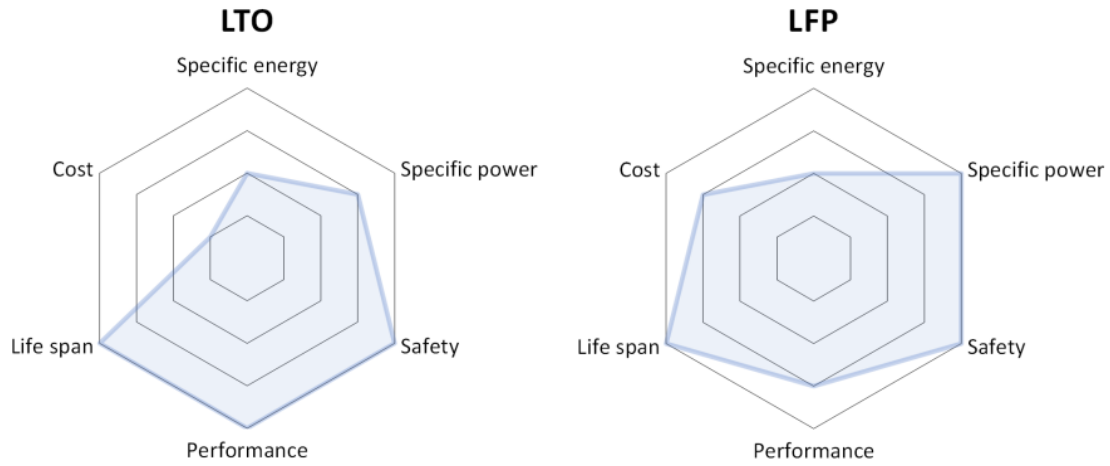

Figure 2. Comparison of LTO and LFP cell 
At the same time, the sample locations for mounting the batteries on the go-kart frame and amount of space needed for batteries were analyzed. It was decided to place batteries symmetrically on both sides of the vehicle. The reason was to evenly distribute the weight of cells on the frame. Different battery cells have different values for energy density and specific energy. Li-Ion cells used in automotive industry (NMC - Nickel Manganese Cobalt, NCA - Nickel Cobalt Aluminum) have much higher these values then LTO and LFP. Table 1 shows the basic parameters of these cells.

Table 1. Specific energy and energy density of Li-Ion cells

\begin{tabular}{lccc}
\hline Li-Ion type & Specific energy $[\mathbf{W h} / \mathbf{k g}]$ & Energy density $[\mathbf{W h} / \mathbf{L}]$ & Cycle life \\
\hline $\mathrm{NCA}$ & $220-260$ & 600 & 500 \\
\hline $\mathrm{NMC}$ & $150-220$ & 580 & $1000-2000$ \\
\hline $\mathrm{LiFePo}_{4}(\mathrm{LFP})$ & $90-160$ & 325 & $>2000$ \\
\hline $\mathrm{Li}_{4} \mathrm{Ti}_{5} \mathrm{O}_{12}(\mathrm{LTO})$ & $60-110$ & 177 & $3000-7000$ \\
\hline
\end{tabular}

Cells which we intend to use for testing (LTO, LFP) have several times smaller amount of energy in mass/volume. Due to the low battery capacity of electric go-kart and the highest priority which is safety, it was decided to continue work based of these two types of cells.

\section{System modelling method}

The motor model was described by two equations (Equation 1,2). The first describes electrical part of electric motor, the second mechanical part [14].

$$
\begin{aligned}
& U_{s}=R_{s} i_{s}+L_{s} \frac{\mathrm{di}_{s}}{d t}+k_{e} \omega_{R} \\
& k_{m} i_{s}=B \omega_{R}+J \frac{\mathrm{d} \omega_{R}}{d t}+M_{s}
\end{aligned}
$$

\section{Where:}

$U_{s}-$ supply voltage

$R_{s}-$ stator resistance

$i_{s}-$ stator current

$L_{s}-$ stator inductance

$k_{e}-$ motor velocity constant, where: $k_{e}=U_{s}-R_{s} i_{s}$

$\omega_{R}-$ rotor rotational speed

$k_{m}-$ motor torque constant

$M_{S n}-$ nominal torque

$B$ - viscous friction coefficient, where: $B=k_{m} i_{s}-M_{S n}$

$J$ - rotor inertia

$M_{s}$ - load torque 
In above equations, input values are voltage U[V], current I[A] and torque $\mathrm{Ms}[\mathrm{Nm}]$. They will vary depending on the type of electric motor, nature of the ride or traveled route.

\section{Case study - electric go-kart}

\subsection{Assumptions for electric go-kart}

The drive and power supply system, which was included in the simulations, is characterized by the following parameters:

- $\quad$ Rated motor power: $10[\mathrm{~kW}]$

- Max RPM(revolutions per minute): 3200

- $\quad$ Rated voltage: $48[\mathrm{~V}]$

- Battery capacity: 40[Ah]

- $\quad$ Estimated working time: 20 minutes

One of the key criteria is to keep the go-kart batteries weight as low as possible and ensure sufficient capacity. During the simulations two types of cells were tested:

- $\mathrm{Li}_{4} \mathrm{Ti}_{5} \mathrm{O}_{12}$ cells: 25 [kg] - 20 cylindrical cells connected in series

- $\mathrm{LiFePO}_{4}$ cells: 20 [kg] - 16 prismatic cells connected in series

\subsection{Power supply system simulation model for light electric vehicles}

Two simulation models were developed - the BLDC (BrushLess Direct-Current) motor model (Fig. 3) and battery discharge model (Fig. 4). The simulation model developed in the MATLAB/Simulink environment is analogous to the general scheme of operation shown in Fig. 1. The combination of two simulation models into one system allowed to analyze:

- how the output power from electric motor loads the power supply system

- energy demand

- estimated operating time of the system for the given driving scenarios.

The data needed to simulate drive system was obtained from manufacturers of electric motors available on the market. Based on the preliminary assumptions, a motor with a rated power of $10[\mathrm{~kW}]$ and a maximum torque of $27[\mathrm{Nm}]$ was selected.

Input values of simulation model were voltage $\mathrm{U}[\mathrm{V}]$ and torque $\mathrm{Ms}[\mathrm{Nm}]$. These two values and internal electric parameters of BLDC motor allowed to obtained in the output two parameters - current I[A] which is drawn from batteries and rotary speed. 


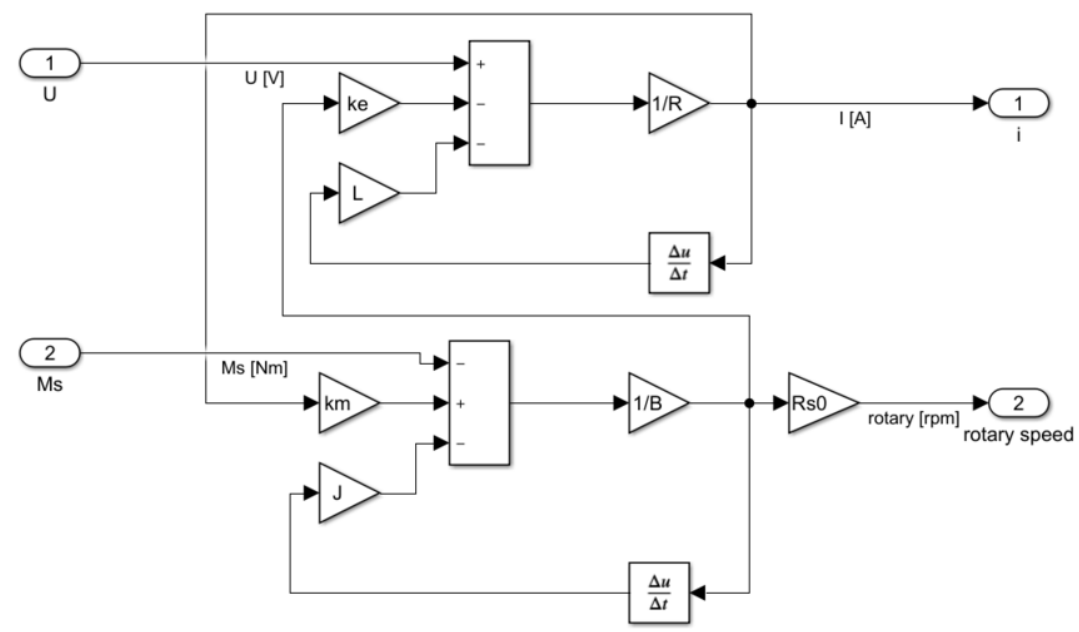

Figure 3. Model of BLDC electric motor

The battery discharge model was developed based on a ready-made library that was modified respectively for LFP and LTO cells. Thanks to this model, it was possible to carry out simulations that will show how the battery will behave after being loaded with set current values. The load current values were taken from output value from the BLDC motor simulation. As the output we received SOC(State of Charge)[\%], current I[A], and voltage $\mathrm{U}[\mathrm{V}]$ of batteries.

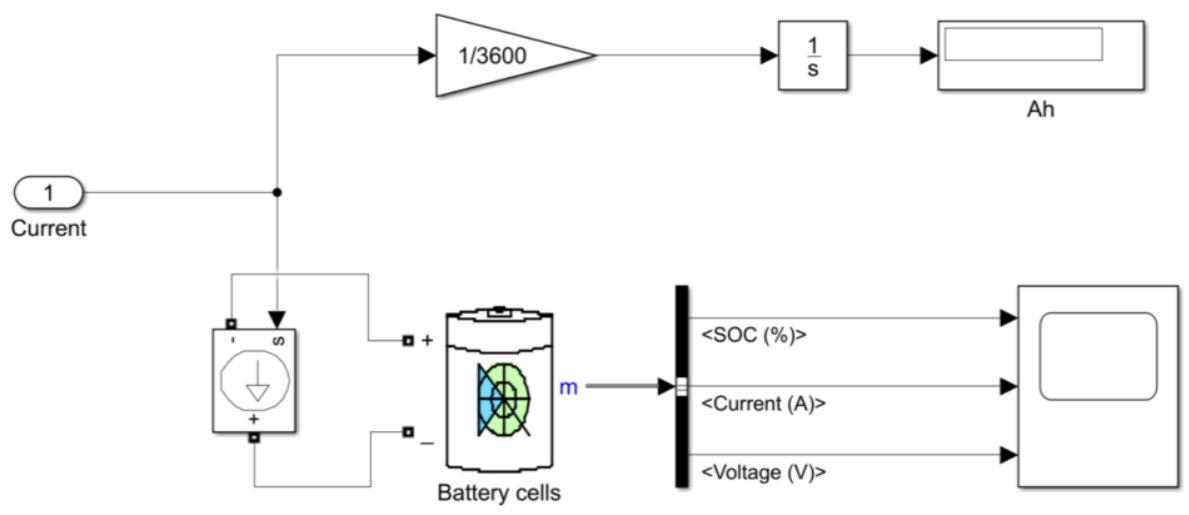

Figure 4. Model of discharging battery cells 


\subsection{Track types for simulation model}

A simulation of driving and energy requirements was developed using simple example of race tracks (Fig. 5). The tracks contain basic elements such as straight lines, bends with different radius and angle. Thanks to them the power supply system can be analyzed in terms of go-kart use in real conditions.
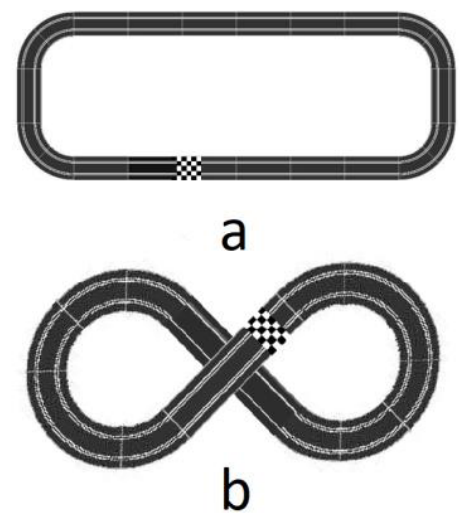

Figure 5. Types of track include in simulation - (a) oval track. (b) eight track

The first scenario is based on an oval track (Fig. 5a). It allowed to analyze the power supply system in terms of rapid changes in speed. After exiting a corner, the accelerator pedal is immediately depressed to the maximum in order to reach the top speed as quickly as possible. This simulation allows to know the driving time on an uncomplicated track. The basic parameters of the track are given below:

- $\quad$ Track length - $270 \mathrm{~m}$

- The length of the longest straight line $-95 \mathrm{~m}$

- Turning radius $-5 \mathrm{~m}$

The second scenario was developed on the basis of the number 8 shaped track (Fig. 5b). On a straight, the vehicle is able to reach maximum speed for a short period of time. Curves on track change the direction of travel by approx. 270 degrees. The simulation shows how much slowing down (approx. $40 \%$ of the route) will affect driving time. The basic parameters of the track are :

- $\quad$ Track length - $165 \mathrm{~m}$

- $\quad$ Straight length - 50m

- Turning radius $-10 \mathrm{~m}$

\subsection{Analysis of energy consumption in various operational states}

Energy demand for various driving phases has been developed using data contained in the catalog of electric motor manufacturer and in the software included with BLDC motor controller. 
Table 2. Electric go-kart energy demand for different driving phases.

\section{Driving phase}

Smooth start

The moment of reaching the maximum speed and maintaining - Rated power

Boost - Peak power

The values of energy demand (Table 2) allowed to present characteristics how the power supply system will discharge during driving. First simulation of discharge was performed for LTO (Fig. 6), second for LFP (Fig. 7).

\section{LTO discharging}

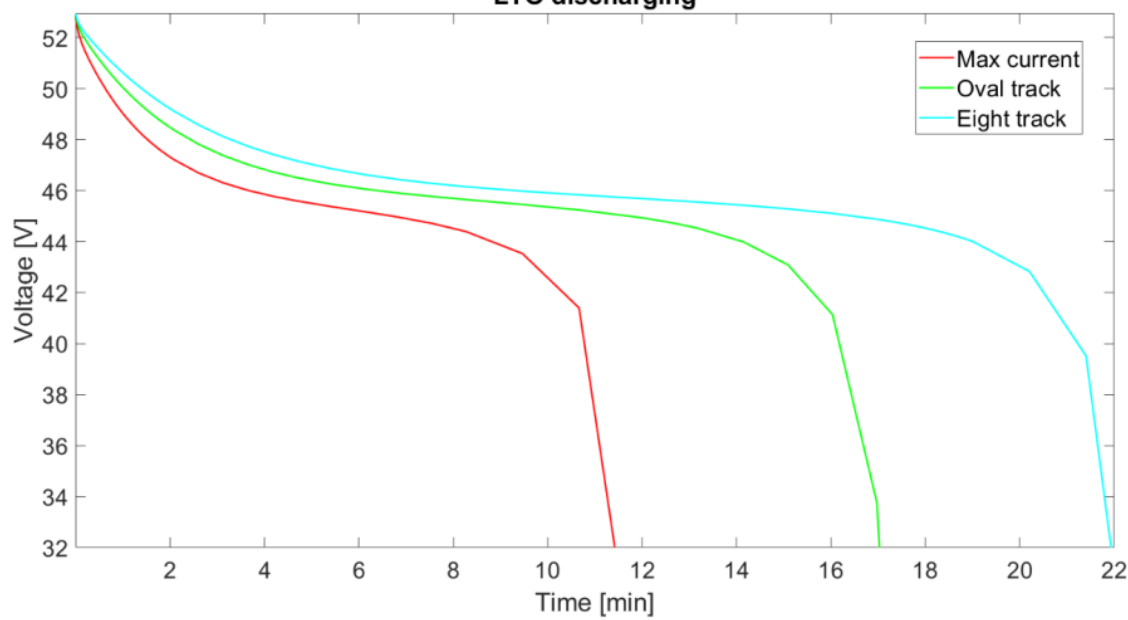

Figure 6. Graph of LTO discharge

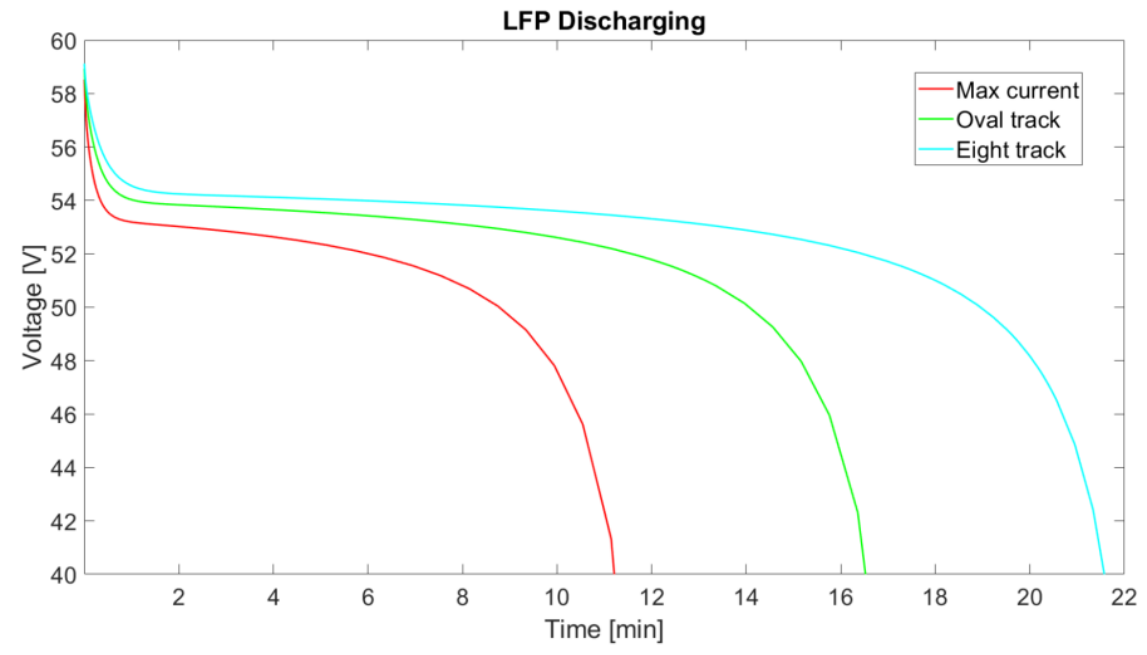

Figure 7. Graph of LFP discharge
Energy demand [kW]

2,5


By analyzing discharge charts of LTO and LFP batteries, it can be concluded that the discharge time of both are very comparable. The discharge characteristics are different from each other. The initial - maximum and final - minimum voltage for both cells are different, therefore the operating voltage of the batteries is also different. Characteristics of the voltage drop depending on the load also different. The biggest difference is the initial discharge period of a fully charged battery.

\section{Conclusions}

Power supply system for electric go-karts is not only the field of electrical engineering, but also mechanics, electronics, programming and chemistry related to the processes taking place inside the cell. We have to consider how many space we have for batteries, in what conditions vehicles will be working or who will be drive a go-kart. We can limit the power of go-kart in the software e.g. if child will drive the kart.

The developed simulation model of power supply system made it possible to analyze operation of two types of battery cells. Thanks to these simulations, it was possible to see how the load acting on the power supply system will affect to the operating time or voltage drop. An analysis of Figures 6 and 7 shows that the battery capacity was selected correctly to the assumptions. The discharging time for both batteries was very similar for each scenario (track). In the tested case study performance and safety are comparable for both batteries, however LFP is approx. 20\% lighter than LTO. Driving time oscillating around 20 minutes is not too high. Increasing the battery capacity 3 times (to achieve 60 mins of driving), the difference between the LFP and LTO batteries will already be $\sim 15$ $\mathrm{kg}$. In the case of racing vehicles, weight can have a significant impact on driving dynamics, travel time (laps) and loads.

In order to better select battery cells for the power supply system, each case should be considered separately. In our case study, we included LTO and LFP due to meeting high security requirements. For different tracks, tracks conditions or other restrictions, a different type of battery cells may be more appropriate. It is important to accurately determine the vehicle operation time necessary to travel the route and the amount of space to install the batteries. Performed simulations allow to know the estimated working time of electric go-kart. Further work must include development of simulation models for battery charging and more advanced trajectory. This second model will allow to observe dynamic changes in the load of batteries.

In order to fine-tune simulation model, it is planned to build a test stand. It will allow to more detailed analysis of the power supply system, among others in terms of voltage drops or overheating of cells. The finally developed simulation model will make it possible to find out about system limitations and critical points at design stage. 


\section{References}

[1] A. Mönnig, C. Schneemann, E. Weber, G. Zika and R. Helmrich, Electromobility 2035:Economic and labour market effects through the electrification of powertrains in passenger cars, IAB Discussion Paper, $8 / 2019$.

[2] B. Sanden and P. Wallgren, Systems perspectives on electromobility, Chalmers University of Technology, Göteborg 2014.

[3] Y. Ding, Z. Cano, A. Yu, J. Lu and Z. Chen, Automotive Li-Ion Batteries: Current Status and Future Perspectives, Electrochemical Energy Reviews, 2019, Vol. 2, Issue 1, pp. 1-28.

[4] Y. Miao, P. Hynan, A. von Jouanne and A. Yokochi, Current Li-Ion Battery Technologies in Electric Vehicles and Opportunities for Advancements, Energies, 2019, Vol. 12(6), 1074.

[5] L. Hollmotz, Safety of Li-Ion Batteries in Vehicles, 23rd International Technical Conference on the Enhanced Safety of Vehicles (ESV), Seoul, Korea, South, 5/2013.

[6] L. Kong, C. Li, J. Jiang and M.G. Pecht, Li-Ion Battery Fire Hazards and Safety Strategies, Energies, 2018, 11, 2191.

[7] W. Skarka, Methodology for the optimization of an energy efficient electric vehicle. In: Proceedings of the 6th International Conference on Integrity-Reliability-Failure, Lisbon, 2018, pp. 415-422

[8] M. Targosz, W. Skarka, P. Przystałka, Model-Based Optimization of Velocity Strategy for Lightweight Electric Racing Cars, Journal of Advanced Transportation, 2018, Article ID 3614025, [Online]. Available: https://doi.org/10.1155/2018/3614025

[9] R. Niestrój, T. Rogala, W. Skarka, An Energy Consumption Model for Designing an AGV Energy Storage System with a PEMFC Stack, Energies, 2020, Vol. 13, 3435.

[10] M. Tyczka, W. Skarka, Optimisation of Operational Parameters Based on Simulation Numerical Model of Hydrogen Fuel Cell Stack Used for Electric Car Drive, Advances in Transdisciplinary Engineering, Vol. 4, 2016, pp. 622-631.

[11] W. Skarka, Model-Based Design and Optimization of Electric Vehicles, Advances in Transdisciplinary Engineering, 2018, Vol. 7, pp. 566-575.

[12] K. Mateja, W. Skarka, Towards energetic autonomy of UAV, Advances in Transdisciplinary Engineering, 2020, Vol. 12, pp. 423-432.

[13] W. Gołębiewski, Concept of the construction of electric Go-kart (ekart), The Archives of Automotive Engineering, 2018, Vol. 80, No.2, pp. 53-63.

[14] A. Hughes, Electric Motors and Drives, Fundamentals, Types and Applications, Third edition, Newews, Amsterdam, 2013. 